\title{
ALGO MÁS SOBRE EL PINTOR DOMINGO SÁNCHEZ CARMONA (1702-1768). NUEVAS APRECIACIONES Y VARIOS RETRATOS ATRIBUIDOS
}

\author{
Juan Alejandro Lorenzo Lima \\ IES Alonso Pérez Díaz, Santa Cruz de La Palma
}

\section{RESUMEN}

La reciente documentación de dos retratos al pintor de La Palma Domingo Sánchez Carmona permite atribuirle otros de igual formato y tipo que guardan semejanza con ellos, por lo que ese hecho sirve de excusa para contextualizar la trayectoria del artista y el valor que dichas representaciones adquieren en la sociedad isleńa del siglo xviII. Deducimos que esta dedicación a la retratística de signo nobiliario pudo convertirse en un medio rentable para Carmona al final de su vida, cuando, tras retornar de Inglaterra, residió temporalmente en Santa Cruz de La Palma y varios pueblos del norte de Tenerife.

Palabras clave: pintura, retrato, Canarias, siglo xvin, Domingo Sánchez Carmona, nobleza.

\section{SOMETHING ELSE ABOUT THE PAINTER DOMINGO SÁNCHEZ \\ CARMONA (1702-1768). NEW APPRECIATIONS AND \\ SEVERAL PORTRAITS ATTRIBUTED}

\section{Abstract}

The recent documentation of two portraits to the painter of La Palma Domingo Sánchez Carmona invites to attribute others of the same format and type that reveal similarity, so that this is an excuse to contextualize the trajectory of the artist and the value that these representations acquier in the island society during the Eighteenth Century. We belive that this dedication to portraiture with a noble sign could become a profitable medium for Carmona at the end of his life, after returning from England and when he lived in Santa Cruz de La Palma and several towns in the north of Tenerife.

KeYwords: painting, portrait, Canary Islands, Eighteenth century, Domingo Sánchez Caroma, nobility. 
La investigación de signo histórico-artístico es imprevisible, porque, cuando menos lo esperas, una pesquisa o un descubrimiento casual ayudan a replantear el significado de ciertas obras. El alcance de dichos hallazgos resulta mayor cuando lo estudiado tiene un carácter inédito y se presta a comparaciones formales, ya que entonces, gracias al análisis del estilo o de los componentes estéticos, advertimos cualidades de utilidad para observaciones posteriores. La dinámica expuesta cobra sentido al vincularse con el objeto de análisis que nos ocupa: varios retratos del siglo XVIII que asociamos con la producción del pintor Domingo Sánchez Carmona (1702-1768), poco valorada hasta ahora ${ }^{1}$. De este maestro conocíamos ya algunos datos biográficos ${ }^{2}$, aunque el descubrimiento de su partida de defunción y del testamento que otorgaba antes de morir abrió nuevas perspectivas para el análisis de realizaciones que pudo afrontar durante la década de $1760^{3}$. Lo publicado acerca de ellas es minoritario y algo contradictorio, por lo que tampoco extraña que dichos trabajos y otros acometidos en La Palma con anterioridad fueran obviados en estudios de caso ${ }^{4}$ e investigaciones regionales sobre pintura, escultura y artes suntuarias. ${ }^{5}$ El desconocimiento de la biografía de Carmona era tal que, incluso, años atrás llegó a confundirse con la de Marcelo Gómez de Carmona (1713-1791), natural también de Santa Cruz de La Palma ${ }^{6}$.

Antes de idear la exposición Vecinos de la ciudad. Retratos en San Cristóbal de La Laguna [siglos XVI-XIX], habíamos reparado ya en una serie de retratos que guardan unidad en lo formal y pudo realizar un mismo artífice a mediados del siglo XVIII. Nuestras primeras deducciones acerca de ellos para atribuirlos a Sánchez Carmona, expuestas en un artículo que no llegaría a publicarse finalmente, fueron confirmadas al advertir que José María Mesa documentó el pago de dos retratos que este autor había realizado a los marqueses de Adeje antes de 1764 [figs. 1-2]. Su última publicación sobre Domingo José de Herrera se ha convertido en un referente para conocer el patrocinio de dicha familia y los usos que sus miembros dieron al arte, aunando por igual lo piadoso, lo suntuario y lo representativo a la hora de reivindicar un linaje que no iba a perpetuarse en el tiempo por carecer de descendencia directa.

${ }_{1}$ Se advierte de entrada que investigadores previos nombraron al artista de un modo cambiante como Domingo Carmona y Cordero, Domingo Sánchez Cordero, Domingo Sánchez Carmona o simplemente Domingo Carmona. En el texto recurriremos a las últimas formas por corresponder con las aducidas en diversos momentos de su vida, ya que, además, él mismo firmó así antes de 1761 .

2 Pérez García, Jaime (2001): Fastos biográficos de La Palma. Santa Cruz de La Palma, 1985-1988, t. III, pp. 21-21; y Los Carmona de La Palma, artistas y artesanos. Santa Cruz de La Palma, pp. 56-57.

${ }^{3}$ Rodríguez Morales, Carlos (2005): «El pintor Domingo Sánchez Carmona (17021768): documentos sobre sus últimos años en Tenerife», Revista de estudios generales de la isla de La Palma, n. ${ }^{\circ}$ 1, pp. 515-519.

${ }^{4}$ Esencialmente Fraga González, María del Carmen (1982): «La pintura en Santa Cruz de La Palma», Homenaje a Alfonso Trujillo. Santa Cruz de Tenerife, t. I, pp. 347-383.

5 Cfr. Hernández Perera, Jesús (1955): Orfebrería de Canarias. Madrid; Rodríguez GonZÁLEZ, Margarita (1986): La pintura en Canarias durante el siglo XVIII. Las Palmas de Gran Canaria; Calero Ruiz, Clementina (1987): Escultura barroca en Canarias (1600-1750). Santa Cruz de Tenerife.

${ }^{6}$ Aclaró ese aspecto Pérez García, Jaime: Los Carmona..., op. cit., pp. 56-57. 


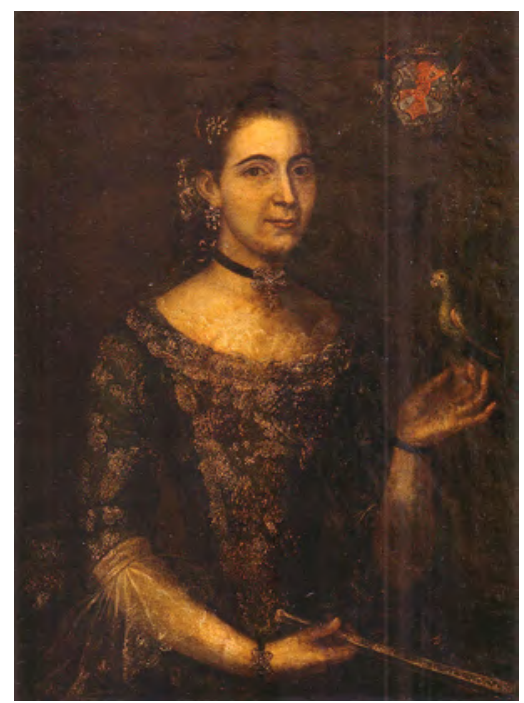

Fig. 1. Domingo Sánchez Carmona: Mariana Leonor Benítez de Lugo y Ponte, marquesa de Adeje y condesa de La Gomera. Colección particular, Las Palmas de Gran Canaria.

Más allá del interés cotidiano o local, los aportes documentales prueban la relación de este comitente y sus delegados mercantiles con maestros de renombre en el medio insular como el aludido Domingo Carmona, el escultor Sebastián Fernández Méndez (1700-1772) o el también pintor José Tomás Pablo (... 1718-1778), entre otros? .

A esas hipótesis e ideas iniciales, ya debidamente contextualizadas y contrastadas, dedicamos ahora un artículo nuevo donde proponemos ampliar el catálogo de Carmona con los retratos de varios nobles que tuvieron relación con él al final de su vida en Tenerife y La Palma. Gracias a ellos se vislumbra un panorama mucho más esperanzador para el estudio del género e incrementamos su obra atribuible, ya que, de no ser así, resultaría imposible aproximarnos a un artista del que apenas conocíamos producción pictórica conservada.

\section{EL PINTOR}

Sorprende que la trayectoria de un autor como Domingo Sánchez Carmona permaneciera tanto tiempo en el olvido, puesto que a principios del siglo XIX Juan Primo de la Guerra recordaba que el clérigo Manuel Díaz (1774-1863) era pariente de «un célebre pintor [...] que años ha floreció en estas islas, el cual salió del país

7 Mesa Martín, José María (2018): «La verdadera historia de la Candelaria de Adeje», Imagen y reliquia. Nuevos estudios sobre la antigua escultura de la Candelaria. La Laguna, pp. 108-127. 


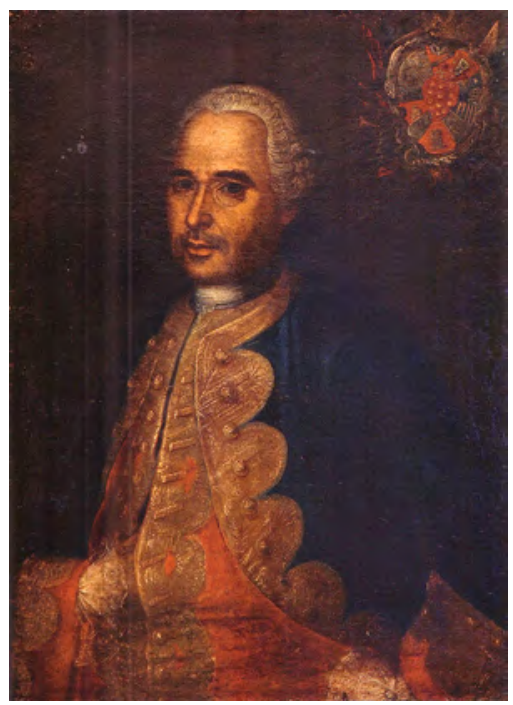

Fig. 2. Domingo Sánchez Carmona: Domingo José de Herrera y Llarena, marqués de Adeje y conde de La Gomera. Colección particular, Las Palmas de Gran Canaria.

y estuvo en Inglaterra»; y afirmó luego que «de su mano está la sala de la casa de Franqui, en la hacienda de Daute, y he visto otros retratos y pinturas suyas muy estimables» ${ }^{8}$. No profundizaremos en esas citas por haberlo hecho antes otros investigadores, pero algunos acontecimientos que se desprenden de ellas merecen una consideración mayor. La biografía de dicho maestro es un fiel testimonio de la época en que se inscribe, aunque, paradójicamente, para el conjunto de los pintores canarios revela datos atractivos e inusuales. Natural de Santa Cruz de La Palma, donde nació en abril de $1702^{9}$, Carmona fue el octavo hijo de un matrimonio bien avenido que contaba con varios parientes y vecinos vinculados al mundo del arte. Ello no impidió que Francisco Sánchez Carmona y Ana Francisca Cordero, sus padres, se desposaran en la parroquia de El Salvador a principios de agosto de $1681^{10}$, porque, al contrario, tal dedicación y el vínculo de varios varones con la Iglesia brindaron un estatus diferente a esta generación de la familia ${ }^{11}$.

${ }^{8}$ Guerra, Juan Primo (1976): Diario. Santa Cruz de Tenerife, t. I, p. 230.

9 Su partida de bautismo aclara que nació el 25 de abril. Fue bautizado en la parroquia de El Salvador el 3 de mayo, apadrinándolo su hermano Francisco Sánchez Carmona, entonces clérigo de menores. Archivo Parroquial de El Salvador, Santa Cruz de La Palma (en adelante APSP): Libro 8 de bautismos, f. $217 \mathrm{v}$.

${ }^{10}$ APSP: Libro 3 de matrimonios, f. $34 \mathrm{v}$.

${ }_{11}$ Cfr. Pérez García, Jaime: Los Carmona..., op. cit., pp. 17-63. 
El afamado cantero Julián Sánchez Carmona (1632-1706) era tío-abuelo de nuestro artífice ${ }^{12} \mathrm{y}$, en un plano más cercano, sus hermanos Diego (1685-1753) y Nicolás (1692-1758) desempeñaron con éxito labores de pedrero y pintor respectivamente ${ }^{13}$. Resulta normal que ese mismo entorno, quizá más inclusivo de lo que advertimos ahora, propiciara la trasmisión del oficio de un modo continuista y conservador. Al respecto conocíamos ya que Cayetano González Guanche (1732-1808), marido de su sobrina María Rosa Carmona de los Reyes (1732-1784), fue igualmente pintor y ayudó a Tomás Rexe (... 1739-1762) en el desempeño de trabajos muy diversos por varios pueblos de La Palma ${ }^{14}$. No extrańa, pues, que Domingo Carmona creciera y se formara junto a esos parientes y otros maestros de estima en el populoso barrio de la Asomada, donde es sabido que convivieron artistas, oficiales de todo tipo y marinos de renombre.

En abril de 1724, cuando alcanzó la edad debida y los medios suficientes para ello, Domingo contrajo matrimonio con Margarita de León. Su esposa era hija de Andrés de León y de Ana de Paz o Pais, parroquianos de El Salvador y avecinados igualmente en "la Somada» o "más allá del Tanque»" La nueva pareja situaría el domicilio familiar -y a buen seguro el taller, parte sustancial de él- en una casa terrera de la calle de los Molinos, puesto que dicha fábrica completaba la dote entregada por sus suegros al tiempo del enlace ${ }^{16}$. Sin embargo, los acontecimientos vitales no favorecieron al pintor en los años siguientes. En mayo de 1724, apenas un mes después del casamiento, fallecía su madre, Ana Francisca Cordero ${ }^{17}$; y en agosto de 1727 Francisco Sánchez Carmona era sepultado también en el convento franciscano ${ }^{18}$. Los testamentos que otorgaron antes de morir confirman que vivían con una situación económica desahogada, al tiempo que revelan un deseo común de beneficiar a todos sus hijos con las decisiones que el clérigo Francisco de los Santos Sánchez Carmona, primogénito y párroco de Las Nieves, iba a adoptar en nombre suyo ${ }^{19}$. No en vano, la existencia de los Carmona Cordero se desenvolvió en un entorno condicionado por la profesión paterna, el vínculo con América y la religiosidad latente en una ciudad proclive a trasformaciones de índole social. De ahí que, por ejemplo, en 1702 obtuvieran el derecho de patronato sobre un altar existente en

12 Existen varias referencias sobre la vinculación de este oficial que trabajó en La Palma, Fuerteventura, Lanzarote y Tenerife con los Carmona Cordero, aunque referimos ahora que en septiembre de 1692 apadrinó a Nicolás, hermano del pintor. APSP: Libro 8 de bautismos, ff. 15v-16r.

13 Pérez García, Jaime: Los Carmona..., op. cit., pp. 53-54.

14 Pérez García, Jaime: Los Carmona..., op. cit., pp. 53-54.

${ }^{15}$ APSP: Libro 5 de matrimonios, ff. 19r-19v.

16 Pérez García, Jaime: Los Carmona..., op. cit., p. 57.

17 APSP: Libro 6 de entierros, ff. 1v-2r.

${ }_{18}$ APSP: Libro 6 de entierros, f. 54r.

19 Archivo General de La Palma (AGP): Fondo de Protocolos Notariales (PN). Legajo 465, ff. 172r-173v (escribano Andrés de la Huerta, 9/5/1724); y legajo 444, ff. 213v-217r (escribano Antonio Vázquez, 1/9/1727). 
la portería del convento de San Francisco, donde colgaba ya «un cuadro de Nuestra Señora de la Concepción ${ }^{20}$.

El vínculo con ese convento resulta clave a la hora de contextualizar los trabajos emprendidos por Domingo, pero también se antoja necesario para conocer todo tipo de acontecimientos familiares. Margarita de León, esposa del artista, era sepultada en su capilla de la Orden Tercera el 31 de julio de $1735^{21}$, aunque la enfermedad que padecía no le impidió testar semanas antes. De lo que manifiesta entonces se desprende que el matrimonio no tuvo hijos y que su coyuntura económica fue compleja en ocasiones, al declarar, entre otros asuntos, que seguían manteniendo algunas deudas. No obstante, designó a su marido como beneficiario de una parte proporcional de los bienes acumulados y del inmueble donde residían, puesto que llegaron a añadirle una segunda planta y darle el «buen estado» que mostraba entonces ${ }^{22}$.

La muerte de Margarita y tal vez la necesidad de buscar un futuro mejor propiciaron la marcha del pintor a Londres, donde era sabido que vivió una larga temporada y contrajo matrimonio con Ana Marlem. Allí nació María Teresa Carmona, su única hija, con quien residía antes de emprender un último viaje a La Palma en torno a 1759. Al testar años después afirmaba que seguía viva junto a su madre «en la ciudad de Londres», de la que él mismo se declaró vecino. Sin embargo, todo parece indicar que no cumplió entonces el deseo de volver a Inglaterra para cuidar de la familia que había dejado atrás. En agosto de 1761 vendió con ese fin la parte proporcional de los bienes que le correspondía por herencia paterna en Santa Cruz de La Palma ${ }^{23}$, pero desde entonces su destino estuvo ligado a la isla de Tenerife. Antes de 1765 decoró el «salón de perspectivas» que existía en la hacienda de Daute, elogiado por Viera y sus compañeros de la Tertulia de Nava; y consta que en 1762 recibió el pago de 50 pesos por componer el Cristo de la Misericordia de la parroquia matriz de Garachico, al «habérsele introducido [tiempo atrás] la traza en todo él». En este caso sabemos que dicha cantidad correspondía exclusivamente a su trabajo como escultor y pintor, ya que no cubrió «la asistencia y manutención [...] por haber sido en la casa de la señora doña Teresa de Alfaro, viuda del coronel don Melchor José Prieto del Hoyo»" ${ }^{24}$.

Esos encargos brindaron a Sánchez Carmona la posibilidad de relacionarse con varios nobles del norte de Tenerife, a quienes, como abordaremos en otro epí-

20 Pérez Morera, Jesús (2000): Magna Palmensis. Retrato de una ciudad. Santa Cruz de La Palma, p. 82.

${ }^{21}$ APSP: Libro 6 de entierros, ff. 201v-202r.

${ }^{22}$ AGP: PN. Legajo 447, ff. 239v-240v (escribano Antonio Vázquez, 22/6/1735).

${ }^{23}$ AGP: PN. Legajo 513, ff. 394r-395v (escribano Pedro Escobar Vázquez, 13/9/1761). Cit. Pérez García, Jaime: Los Carmona..., op. cit., p. 57.

${ }^{24}$ Rodríguez Morales, Carlos: «El pintor Domingo...», art. cit., pp. 516-517. Sobre esa imagen, su materialidad y filiación artística, véase Amador Marrero, Pablo F. (2010): «El Santo Cristo, reliquia muy milagrosa. Análisis interdisciplinario de una imagen novohispana de papelón», Garachico y sus fiestas del Cristo. Apuntes históricos y crónicas de prensa. Garachico, pp. 29-53. 
grafe, retrataría antes de fallecer en 1768 . No extraña, pues, que la muerte le sorprendiera mientras residía en La Orotava junto al coronel Juan Francisco Domingo de Franchy, de cuyo domicilio fue llevado al convento de San Benito para recibir sepultura el 27 de marzo de aquel ańo. En el testamento que dictó horas antes Domingo encargaba a dicho aristócrata y a su hijo, el teniente coronel Antonio de Franchy, que organizaran el entierro y distribuyeran sus propiedades entre los amigos y familiares que enumera, residentes en Tenerife, La Palma e Inglaterra ${ }^{25}$. De ahí que el mismo Antonio de Franchy pidiese seis capellanes de la parroquia matriz para solemnizar el sepelio y cumpliese luego lo estipulado por el difunto, quien era descrito en esos momentos como "residente [y no vecino] de la Villa de La Orotava» ${ }^{26}$. Concluía así la vida de un maestro culto e itinerante, cuyos últimos ańos de actividad profesional en el Archipiélago pueden conocerse mejor gracias al entramado de relaciones y amistades que forjó a su alrededor.

\section{AUTOR POLIFACÉTICO Y CON UNA OBRA DIVERSA. RETRATISTA DE MÉRITO}

Indicábamos antes que, a pesar de la información tan escueta que nos brindan muchos documentos, la trayectoria vital y profesional de Domingo Sánchez Carmona resulta interesante si es comparada con la de otros artistas canarios del siglo XVIII. Pese a ello, nuestras propuestas de análisis son aún deducciones e hipótesis de trabajo, argumentadas a partir de lo sucedido con un autor polifacético y sujeto a la tradición local. Por eso mismo creemos probable que sus inquietudes creativas se alentaron en contacto con el arte flamenco y andaluz conservado en La Palma, si bien el entorno inmediato quedó supeditado a otra saga de maestros con fama en aquellos momentos: los Silva. De haberse producido allí, su formación no sería ajena a lo realizado de forma exitosa por Bernardo Manuel de Silva (1651-1725) y su hijo Juan Manuel de Silva Vizcaíno (1687-1751), quienes perpetuaron un estilo amparado en el acomodo de dichos referentes a la idiosincrasia isleña ${ }^{27}$. En ese contexto la movilidad tampoco resultaría ajena al joven Carmona, aunque, dada la singularidad del núcleo familiar, es posible que desde la niñez tuviera un conocimiento real de lo ocurrido lejos de La Palma. Algunos parientes suyos eran marinos y muchos residieron o mantenían un trato continuo con el Nuevo Mundo, ya que, sin ir más lejos, su padre es citado a menudo como «hombre de la mar» $\mathrm{y}$ «mareante»; y pasados los años, Francisco Sánchez, uno de sus hermanos mayores, obtendría las órdenes de diácono y clérigo en La Habana ${ }^{28}$.

rros, ff. $3 \mathrm{r}-3 \mathrm{v}$.

25 Rodríguez Morales, Carlos: «El pintor Domingo...», art. cit., pp. 516-518.

${ }_{26}$ Archivo Parroquial de Nuestra Señora de la Concepción, La Orotava: Libro 9 de entieCruz de Tenerife.

${ }^{28}$ Pérez García, Jaime: Los Carmona..., op. cit., pp. 51-52. 
Lo sorprendente es comprobar que no haya constancia de una vinculación continua de Domingo con el trasiego oceánico y que, como sabemos, durante una temporada larga se avecindara en la ciudad de Londres, algo extraordinario porque la residencia allí coincide con una época conflictiva para las relaciones hispano-británicas. De acuerdo a lo vivido entonces, la capital inglesa ofrecía múltiples posibilidades para un maestro que al final de su vida pudo especializarse en la pintura decorativa, el retrato y las composiciones de género. En cualquier caso, no sabemos si durante el tiempo en que estuvo fuera del Archipiélago se dedicó reiteradamente al ejercicio de las artes plásticas o a cuanto derivaba de él con un sentido práctico.

Los éxitos conocidos de su trayectoria previa en Santa Cruz de La Palma se vinculan en mayor medida con el quehacer escultórico, algo común para otros autores del mismo contexto. Maestros previos como Antonio de Orbarán (16031671) o el ya citado Bernardo Manuel de Silva ganaron fama en la isla como artistas y hombres de saberes polifacéticos, en consonancia plena con el tiempo que les tocó vivir; y como sus contemporáneos Juan Manuel de Silva y Tomás Rexe, Sánchez Carmona recurrió a varias manifestaciones creativas para atender una demanda creciente e irregular, amparada en novedades que el siglo XVIII impuso para superar modismos de la centuria anterior.

Esa primera fama o reputación pudieron cimentarla las pocas esculturas de su autoría que conocemos ahora: la Virgen de los Dolores del antiguo convento franciscano (c. 1732) y una Santa Margarita de Cortona (1734) a la que dieron culto los miembros de la Orden Tercera, pendientes de un estudio contextualizador que nos ayude a descubrir su originalidad. A ellas se han sumado otras atribuidas como los ángeles que complementan algunos tronos de la iglesia conventual ${ }^{29}$ y un busto femenino que conservaba Alberto José Fernández García, reconvertido en una de las mujeres que integran el conjunto procesional de las Tres Marías en la parroquia de El Salvador ${ }^{30}$. La primera, muy elogiada desde el mismo tiempo de su ejecución, responde a un encargo de la cofradía de la Vera Cruz y fue esculpida en el periodo 1729-1732, ya que los asientos contables del mayordomo consignaron entonces el pago de 200 pesos por la hechura ${ }^{31}$. Además, es probable que compusiera la repre21/11/2013.

29 Pérez García, Jaime: Los Carmona..., op. cit., p. 56.

${ }^{30}$ Cfr. «Recuperan la escena de las Tres Marías para la Semana Santa», El Apurón,

31 Conviene puntualizar la cronología de 1733 ofrecida a menudo para esta escultura de candelero, ya que el descargo de su adquisición se inscribe en las cuentas del mayordomo Juan Antonio Vélez y Guisla correspondientes al periodo 1729-1732, no aprobadas hasta el tiempo de la presentación en junio de 1733. En ellas se alude explícitamente al pago de 200 reales por «el costo de una imagen de la Soledad de vestir: los ciento y cincuenta que llevó Domingo Carmona por su hechura y los cincuenta restantes que se gastaron en madera, clavos y oficial que le formó el cuerpo; y no se pone el vestido que se añadió y compuso porque hace gracia dicho mayordomo». A pesar de lo manifestado en ocasiones, esta nueva obra reemplaza a una anterior que los mayordomos de la misma cofradía inventariaron en 1681, cuando era vestida con «saya de bayeta y manto de anascote, y unas tocas de gasa y otras de lino». Fue exhibida en un retablo de amplia hornacina que poseía su capilla, junto a un Cristo Crucificado «de estatura de hombre» y las efigies también vestideras de San 
sentación previa de San Juan Evangelista que hizo pareja con ella, ya desparecida, cuyo pago registran las cuentas de esa corporación al mismo tiempo ${ }^{32}$.

Tal notoriedad esconde una más que probable dedicación de Domingo a la pintura, puesto que algunos documentos previenen sobre encargos recibidos en aquel momento. Así, por ejemplo, antes de viajar a Tenerife había realizado varias obras para decorar la hacienda de la Quinta Verde de Santa Cruz de La Palma, entonces propiedad de Nicolás Massieu Salgado (1720-1791). Al margen de un retrato que hizo de dicho comitente, pintó para él dos cuadros alusivos al señorío de Lilloot y dos más sobre las guerras en que intervino Pablo Vandale durante el siglo Xvi, alusivas a la gloria de sus antepasados y a los Países Bajos ${ }^{33}$. Ambas composiciones, perdidas o no identificadas en nuestro tiempo, podrían valorarse por dicha descripción como escenas de historia y recreaciones de paisaje, temáticas que no resultan comunes para los autores locales del Setecientos.

Lo mismo podría decirse de su dedicación posterior a las pinturas de simulación arquitectónica en las paredes, recurriendo en lo esencial a juegos perspectívicos. Es probable que la notoriedad de estas soluciones efectistas sea en parte un mérito suyo, ya que la documentación de algunos trabajos durante la década de 1760 antecede a los repertorios que José de Sala (... 1729-1789...) y Cristóbal Afonso (17421797) pusieron de moda en Tenerife décadas después. Aludíamos antes el «salón de perspectivas de Carmona» que mencionaron los miembros de la Tertulia de Nava a raíz de su visita a la hacienda de Daute en 1765 , tal vez la primera manifestación solvente de un tipo ornamental que recordó años después el vizconde del Buen Paso ${ }^{34}$. Sin embargo, decoraciones de esa naturaleza pudieron existir en otros complejos residenciales del norte, no conservados ya o muy intervenidos luego.

Sabemos que al tiempo de su muerte Carmona vivía en la casa familiar que los Franchy edificaban desde de 1745 en La Orotava, un inmueble de amplias dimensiones que llamó la atención de vecinos y foráneos por la bondad de su arquitectura, el modismo a la europea que asumieron los propietarios y lo vistoso del jardín inmediato ${ }^{35}$. Construido por el coronel Juan Francisco Domingo de Franchy, antes aludido, su imagen fue idealizada en dos grabados que Freudenberg y Cattoir firmaron antes de acabar el siglo [fig. 3], por lo que no extrańa que el artífice encontrara en ese entorno un ambiente privilegiado para residir una temporada y quizá trabajar esporádicamente como pintor y escultor. La destrucción del edificio a raíz de un incendio producido en 1905 nos priva ahora de conocerlo bien, aunque las

Juan y la Magdalena que completaron el misterio del Calvario. APSP: Libro de cuentas y acuerdos de la cofradía de la Vera Cruz, ff. 1r, 54v. Fernández García, Alberto José: «Notas históricas de la Semana Santa de Santa Cruz de La Palma», Diario de Avisos, 5/4/1963.

32 APSP: Libro de cuentas y acuerdos de la cofradía de la Vera Cruz, f. 55r.

33 Pérez García, Jaime: Fastos biográficos..., op. cit., p. 57.

${ }^{34}$ Guerra, Juan Primo: Diario..., op. cit., t. I, p. 230.

35 Cfr. Martín López, David (2008): «La casa de Franchy en La Orotava: megalomanía y estética arquitectónica en Canarias (1745-1908)», XVII Coloquio de Historia Canario-Americana (2006). Las Palmas de Gran Canaria, pp. 1352-1362. 


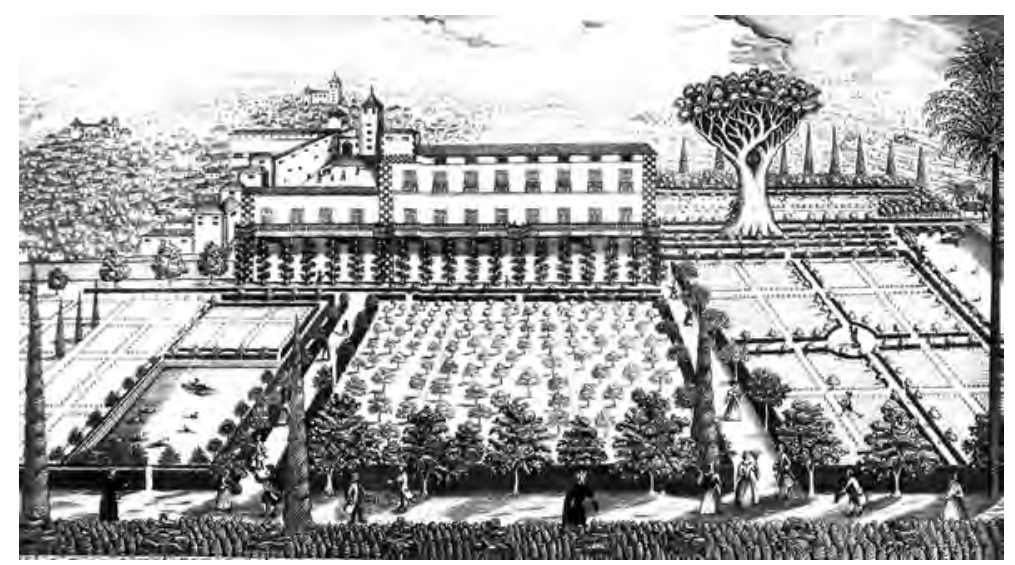

Fig. 3. Simon Cattoir y C. de Freudenberg: Casa y jardines de Franchy en La Orotava. Colección particular, Tenerife.

descripciones que poseemos de él, debidas en gran medida a André Pierre Ledru, Sabin Berthelot y otros eruditos del siglo XIx, se centran por lo general en su jardín y en el drago milenario que lo presidía, derribado en 1867. No obstante, quisiéramos llamar la atención sobre apuntes que evocan el patrimonio perdido entonces, ya que algunos artículos de prensa y notas manuscritas mencionan los trabajos que Sánchez Carmona pudo afrontar en dicho domicilio antes de 1768. Nicolás Perdigón (1853-1939), por ejemplo, anotaba en su diario que con el fuego desparecieron las «pinturas muy antiguas de arquitectura que decoraban algunas salas» $\mathrm{y}$ «los retratos de sus poseedores", entre los que se encontrarían al menos varios trabajos de Feliciano de Abreu (... 1655-1706) ${ }^{36}$. Resulta lógico, pues, que las estancias principales de la casa contaran con efigies suyas y que esos mismos espacios fueran ornamentados con simulación perspectívica por nuestro pintor durante el tiempo de residencia en La Orotava. Esta idea avala la cercanía hacia el coronel Juan Domingo de Franchy y su hijo Antonio, puesto que en el testamento dictado antes de morir nombró al último albacea por la «mucha satisfacción» que le tenía ${ }^{37}$.

El vínculo del artista palmero con los Franchy creemos que se pone de manifiesto en sendos retratos que han llegado a nuestro tiempo y pueden atribuírsele [figs. 7-8], pero esa circunstancia no es privativa de dicha familia. Sabíamos ya que en Santa Cruz de La Palma pintó al menos uno de Nicolás Massieu Salgado y que su primera aproximación al género, proclive siempre a la pompa nobiliaria, no fue ajena a modismos vigentes en el entorno natal y formativo. A día de hoy no abundan retratos antiguos en La Palma, si bien la documentación previene que exis-

\footnotetext{
36 Archivo Familia Perdigón, La Orotava: Sign. D-Iv. Cuaderno de citas, sin clasificar ni paginar.

37 Rodríguez Morales, Carlos: «El pintor Domingo...», art. cit., p. 517.
} 


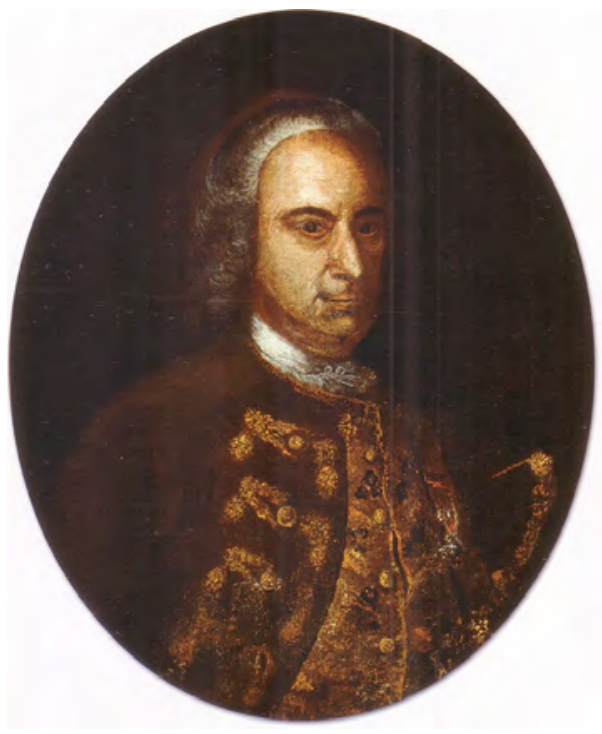

Fig. 7. Atribuido a Domingo Sánchez Carmona: Juan Bautista de Franchy y Benítez de Lugo, marqués de El Sauzal. Colección particular, La Orotava.

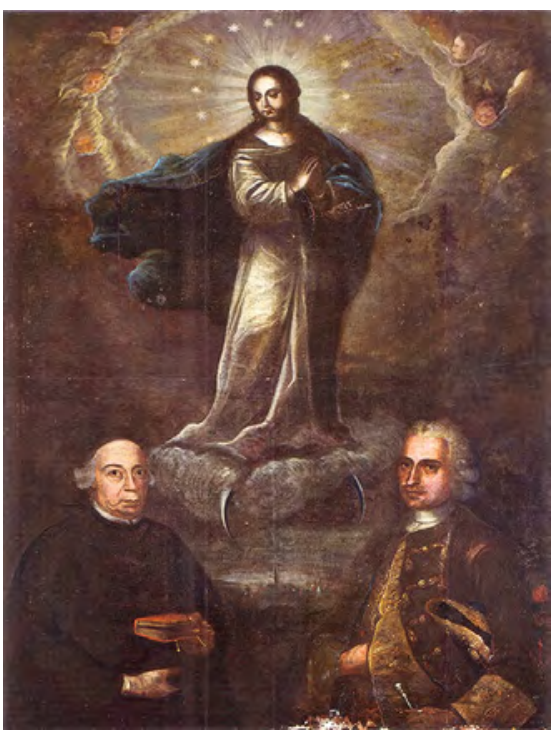

Fig. 8. Atribuido a Domingo Sánchez Carmona: Inmaculada con retratos de la familia Franchy, Ermita de Nuestra Señora del Carmen o de Franchy, La Orotava.

tieron en gran número y quizá con distinto formato, técnica y acabado. Al citado Juan Manuel de Silva se atribuyen algunos ${ }^{38}$, y otros que permanecen inéditos, tal vez realizados por Tomás Rexe, ayudan a comprender el convencionalismo que los pintores de aquella isla revelaron a veces como fisonomistas. Sirva de muestra en ese sentido la efigie protocolaria del primer marqués de Guisla (colección particular, Santa Cruz de La Palma), hasta ahora anónima y fechable antes de 1765, cuyo discreto acabado nos previene sobre unas maneras que reivindicaban más el aparato o la apariencia que el apurado técnico [fig. 4].

Intuimos que un bagaje afín es el que Domingo Carmona adquirió al tiempo de marchar a Londres después de 1735, aunque allí, en una de las ciudades más cosmopolitas de Europa, ya triunfaban como retratistas los pintores Jonathan Richardson (1667-1745), George Knapton (1698-1778) y Thomas Hudson (1701-1779), entre otros $^{39}$. La vuelta al Archipiélago le deparó la posibilidad de convertirse en un autor de referencia para la nobleza local, tal vez debido al prestigio que conllevaba la residencia previa en Inglaterra. Durante la década de 1760 Carmona pintó varios retratos en el norte de Tenerife, estando bien documentados los concernientes al marqués

38 Pérez Morera, Jesús: Silva..., op. cit., pp. 151-153.

${ }^{9}$ Cfr. Polnton, Marcia R. (1993): Hanging the head: portraiture and social formation in Eighteenth-Century England. Yale. 


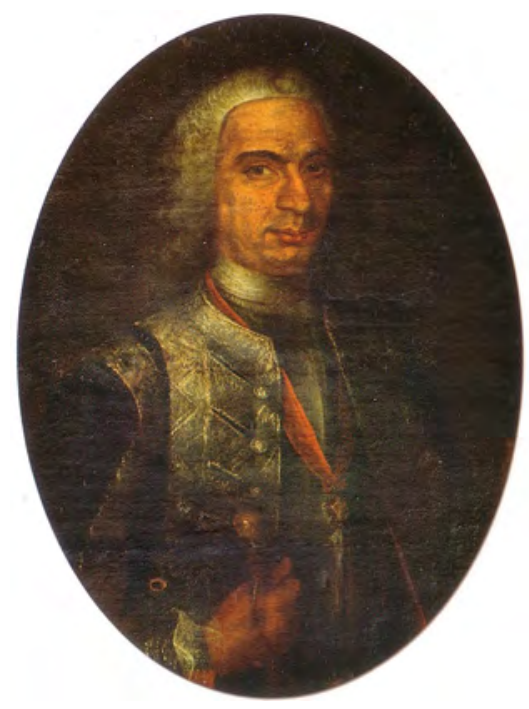

Fig. 4. Anónimo: Juan Domingo de Guisla y Boot, marqués de Guisla. Colección particular, Santa Cruz de La Palma.

de Adeje y su mujer que cobró a principios de 1764 [figs. 1-2]. A partir de ellos pueden atribuírsele cuatro más, cuyo acabado no ofrece duda por su evidente proximidad en lo compositivo y lo formal [figs. 5-8]. No es casual que fuera este género el que le diera fama con posterioridad, porque, como señalábamos antes, Juan Primo de la Guerra anotó en 1807 que había visto otros retratos suyos «muy estimables» ${ }^{40}$.

En el epígrafe siguiente nos detendremos a comentar los aportes de Sánchez Carmona a la retratística isleña, pero de entrada se antoja notorio que sus lienzos introdujeran variantes en lo relativo a formatos y composiciones. Además, es probable que también trabajara el género del retrato con otros fines, ya que a la hora de testar en 1768 menciona «una pintura de Nuestra Señora de Candelaria» que custodiaba un vecino de Santa Cruz de Tenerife y legaba a su sobrina María Antonia Carmona, residente en La Palma ${ }^{41}$. Se ha sugerido la posibilidad de que ese cuadro y otro de la Virgen de los Dolores referido en el mismo documento sean obras de su autoría, por lo que, de ser así como suponemos también, habría que asociar a Carmona con la pintura devocional e incluirlo en la larga nómina de pintores que efigiaron a la Candelaria durante el siglo XVIII ${ }^{42}$.

40 Guerra, Juan Primo: Diario..., op. cit., t. I, p. 230.

${ }^{41}$ Rodríguez Morales, Carlos: «El pintor Domingo...», art. cit., p. 517.

42 Rodríguez Morales, Carlos (2009): «Espejos marianos. Retratos y retratistas de la Candelaria", Vestida de sol. Iconografía y memoria de la Virgen de Candelaria [catálogo de la exposición homónima]. La Laguna, pp. 31-57. 


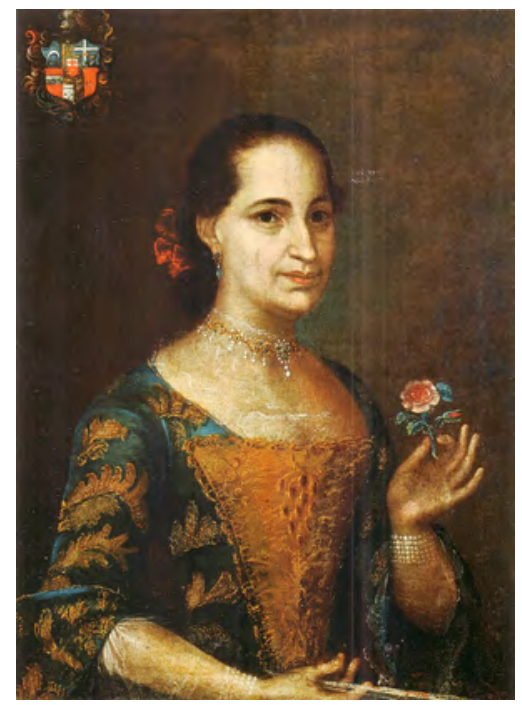

Fig. 5. Atribuido a Domingo Sánchez Carmona: Laureana de Alfaro y Poggio. Colección particular, Los Realejos.

\section{RETRATOS PARA LA NOBLEZA}

A día de hoy las dotes pictóricas de Domingo Sánchez Carmona son conocidas gracias a varios retratos que ejecutó al final de su vida, aunque la dedicación del maestro a dicho género no fue exclusiva ni continuada en el tiempo. A pesar de esa circunstancia, tiene que ponderarse su capacidad como fisonomista y creador de imágenes arquetípicas, quizá más relacionadas entre sí de lo que advertimos ahora. En algunos retratos que pintó durante la década de 1760, los únicos que conocemos de su mano y otros que le atribuimos ahora, aflora el saber de un autor que se enfrenta al lienzo con audacia y un convencimiento pleno de lo que está reproduciendo [figs. 1-2]. De ahí que esas realizaciones sean en muchos casos un producto común y reiterado, donde, como ya se ha advertido, prima la idea o el valor conceptual y no tanto la destreza técnica. Tal pormenor explica que las formas se repitan constantemente y que, más que una efigie singular y pensada de modo concreto para cada modelo, reproduzcan de forma genérica el ideario dominante cuando medió el siglo xviII. En dicha cualidad Carmona se revela como un pintor apegado a la tradición isleña, contrario a los derroteros que dicha manifestación mostraba ya como vanguardia en Inglaterra ${ }^{43}$. Así pues, no parece extrańo que su arte encajara

43 AA.VV. (2001): Art and culture in the Eighteenth-Century. New dimensions and multiple perspectives. Londres; RETFORD, Kate (2006): The art of domestic life: family portraiture in the Eighteenth-Century England. Yale. 
a la perfección con las pretensiones de la oligarquía local y que en él muchos modelos encontrasen un paradigma de los modos y las costumbres que les había tocado vivir. Esa condición tampoco lo distancia de otros autores de aquel tiempo, ya que, sin ir más lejos, en el fondo y las formas sus efigies masculinas no son tan diferentes de la representación de Fernando de la Guerra y del Hoyo (1734-1799) que José Rodríguez de la Oliva (1695-1777) firmó en $1752^{44}$.

Como señalamos por último, en los retratos de la nobleza isleña pintados entonces subyace un sentimiento común, tendente a reproducir las modas impuestas en tiempos de Fernando VI para simplificar los ademanes y excesos que la etiqueta borbónica había popularizado desde principios del siglo. De ahí que en el caso de los hombres primen el uso de pelucas con menor volumen y prendas confeccionadas con terciopelos lisos o escasamente bordados, no ya con sedas coloristas; y en lo relativo a las damas, su apariencia simplificó también peinados, atuendos y adornos suntuarios, procurando una imagen más directa y natural de esas mismas mujeres que no escondían el estatus consustancial a su condición privilegiada ${ }^{45}$.

Las cualidades descritas tienen un acomodo fácil en dos retratos de Sánchez Carmona que revelan mayor calidad: los relativos a Domingo José de Herrera y Llarena (1714-1766) y su mujer, Marina Leonor Benítez de Lugo y Ponte (17271808), marqueses de Adeje y condes de La Gomera [figs. 1-2]. El encargo de esta pareja de efigies, ideada para su exhibición conjunta, coincide con un momento clave en la vida de los modelos, ya que durante la década de 1760 vivieron con frustración su incapacidad de tener descendencia y perpetuar así un linaje de tanto lustre para la sociedad isleña. Pese a ello, Domingo José inmortalizó desde fecha previa su recuerdo como un hombre dadivoso y espléndido respecto a las manifestaciones artísticas, por lo que acabaría costeando toda clase de obras que favorecieron a la parroquia de Santa Úrsula, el convento franciscano y la Casa Fuerte de Adeje ${ }^{46}$.

Los retratos que codificaron la imagen del matrimonio como unos nobles cultos e instruidos adquieren un protagonismo extremo en ese contexto de reivindicación social, resultando equiparables, por ejemplo, al alto número de escudos e inscripciones que muestran las piezas y los edificios de su patrocinio o tutela. Por eso mismo no extraña que en enero de 1764 Domingo Carmona recibiera la elevada suma de 1000 reales para cubrir el coste de sus cuadros, un pago efectivo gracias a los fondos que el marqués depositó en la casa comercial Viuda de Blanco e

${ }^{4}$ Cfr. Fraga González, María del Carmen (1983): Escultura y pintura de José Rodríguez de la Oliva (1695-1777). La Laguna, pp. 65-66.

45 Lorenzo Lima, Juan Alejandro (2015): «De una pintura y su tiempo. José Jacinto de Mesa y Castilla, retratado por Juan de Miranda», Consejo Consultivo de Canarias. Fondo patrimonial. La Laguna, pp. 19-53.

46 No nos detendremos a comentar esa circunstancia, al haberlo hecho con abundantes datos y noticias inéditas Mesa Martín, José María: «La verdadera historia...», art. cit., pp. 105-127. Para la biografía de ambos y sus retratos, véase Nobiliario de Canarias. La Laguna, 1952-1967, t. III, pp. 165-167/láms. CCCXII-CCCXIII. 
Hijos del Puerto de la Cruz ${ }^{47}$. Además, cabe la posibilidad de que en fecha previa ambos modelos posaran ante el pintor a raíz de una estancia prolongada en la hacienda que habían edificado en el pago de El Durazno, no muy lejos de La Orotava. Sea como fuere, lo importante ahora es la elección de un autor poco conocido como Carmona a la hora de afrontar un encargo tan importante, ya que otros pintores del norte trabajaron para los marqueses a través de peticiones que sus agentes mercantiles formulaban a menudo y costeaban con el crédito disponible en la casa Blanco. De ahí que, por ejemplo, el maestro José Tomás Pablo decorase antes de agosto de 1764 las puertas del órgano alemán que Domingo José había obsequiado a la parroquia de Adeje y después del verano de 1765 policromara, encarnara y barnizara las imágenes de la Candelaria y Santa Úrsula que el escultor Sebastián Fernández Méndez concertó para dicho templo ${ }^{48}$. El mismo Pablo pudo dorar los marcos de ambos lienzos junto a una venera, puesto que los registros de contabilidad de la Casa Fuerte revelan un pago de 100 reales con los que cubrir esa labor y otra partida adicional de 56,2 reales que había importado el material necesario para «dorar las guarniciones de los retratos $»^{49}$.

Estas efigies constituyen un testimonio útil a la hora de calibrar las pretensiones nobiliarias de sus comitentes, cuestión a la que todos los implicados dieron respuesta con maestría. Su valor es tal que nos ayudan a vislumbrar un prototipo convencional de figura nobiliaria, cuya repetición e interpretación por parte del pintor en un corto periodo de tiempo previene sobre una popularidad que se tornaría de inmediato en éxito y reconocimiento. Suponemos que en estas efigies -o quizá en otras anteriores, no conocidas ahora- Carmona definió un modelo poco novedoso y muy eficiente por su alta representatividad social, tendente a concentrar elementos comunes a la retratística de siglos anteriores. La singularidad del autor aflora en el modo en que resuelve los presupuestos técnicos y el acabado conferido a modelos de un estatus afín, proclives siempre a una indeterminación leve de las mismas formas que describen sus cuerpos por medio de atributos, atuendos y otros abalorios suntuarios. Así, al margen del mayor o menor grado de indefinición que les conceda, Carmona dispone habitualmente a los efigiados sobre un fondo neutro que tiende a gamas oscuras y de frente o ligeramente ladeados respecto a un rostro de posición hierática, encuadrando la vista usual de tres cuartos para ceñir la representación a algo más de medio cuerpo [fig. 2].

En el caso de los hombres esconde a menudo las manos en un lateral y dentro de la chupa o casaca, pudiendo portar a veces el tricornio que complementa su vestimenta. Más detallista se revela en el caso de las efigies femeninas, puesto que habitualmente las modelos portan en las manos atributos que aluden a su condi-

47 Archivo de El Museo Canario (en adelante AEMC): Fondo Casa Fuerte de Adeje. Sign. 039005, f. 57. Cit. Mesa Martín, José María: «La verdadera historia...», art. cit., p. 121.

${ }^{48}$ Mesa Martín, José María: «La verdadera historia...», art. cit., pp. 120-121, 124-127.

49 AEMC: Fondo Casa Fuerte de Adeje. Sign. 039005, f. 58. Cit. Mesa Martín, José María: «La verdadera historia...», art. cit., p. 121. 
ción de mujer noble e incitan lecturas simbólicas ${ }^{50}$. Al margen de esa distinción, es común la presencia de escudos muy compartimentados con cuarteles en un extremo de la parte superior, no mostrando líneas rectas en sus perfiles ni en los remates por el ornato de signo dieciochesco que los enmarca. Con todo, resulta significativo el detenimiento puesto en los rostros y en la descripción de algunos detalles para advertir diferencias sustanciales, quizá explicables si nos atenemos al precio que este tipo de recreaciones alcanzaba ya en el Archipiélago ${ }^{51}$.

En el caso de los retratos que tratamos de Domingo José de Herrera y Mariana Leonor Benítez de Lugo esos cambios confieren una vistosidad mayor a las que son ahora sus únicas efigies conocidas, algo que, por ejemplo, es perceptible en la destreza que el pintor manifiesta a la hora de recrear los galones de la casaca del marqués o la pose que dicho personaje adopta solemnemente, ya como un hombre de edad avanzada. Mayor detenimiento se observa en la representación de la marquesa consorte, cuyo interés estriba en la descripción que Sánchez Carmona nos brinda de su traje de tonos oscuros con escote generoso y mangas amplias, mostrando en los extremos el encaje fino de costumbre. La vanidad que es consustancial al estatus nobiliario queda de manifiesto en el juego de joyeles que la joven Mariana muestra en ambas muñecas, el pecho, las orejas y el cabello recogido atrás. Complementa su representación el abanico que porta en una de las manos y el ave exótica en la otra, quizá un loro como alusión velada al refinamiento que era inherente a sus poseedores durante la época Moderna ${ }^{52}$.

Gran semejanza con los anteriores muestran los retratos hasta ahora anónimos de Félix Poggio Valcárcel (1728-1793) y su mujer, Laureana de Alfaro y Poggio (1731-1807), que atribuimos por esa razón a Sánchez Carmona [figs. 5-6]. No debe obviarse que los modelos constituían un matrimonio de alta estima en Santa Cruz de La Palma, donde transcurrió buena parte de su vida y donde suponemos que el pintor pudo efigiarlos en torno a $1761^{53}$. El paralelismo de ambas obras respecto a las anteriores es tal que parecen producto de un mismo patrón o modelo, apenas modificado por la descripción de los atuendos y algunos atributos. Esta relación se observa sobre todo en el caso de la efigie femenina, ya que la figuración de Laureana de Alfaro da cabida a un traje de gran vistosidad y colorido, acaso confeccionado con los tejidos lyoneses que eran demandados en aquel momento desde el Archipiélago. Luce cabello recogido atrás por medio de un lazo de color rojo, portando en las manos el abanico distintivo y una pequeña rosa como sinónimo de feminidad o

50 Algunas no son contrarias a lo señalado inicialmente por GÁLLEGo, Julián: Visión y símbolos de la pintura española del Siglo de Oro. Madrid, 1987.

${ }^{51}$ Lorenzo Lima, Juan Alejandro (2018): Vecinos de la ciudad. Retratos en San Cristóbal de La Laguna (siglos XVI-XIX) [catálogo de la exposición homónima]. La Laguna, pp. 13-25.

52 Gómez-Centurión Jiménez, Carlos (2010): «Virtuosos e impertinentes: los pájaros de cámara en la corte española del siglo xviıI», Bulletin for Spanish and Portuguese Historical Studies, n. ${ }^{\circ} 35$, pp. 108-115.

53 Para la biografía de ambos personajes, véase AA. VV.: Nobiliario de Canarias..., op. cit., t. III, pp. 837-842. Los retratos fueron reproducidos por vez primera como láms. CCCLXXIII-CCCLXXIV. 


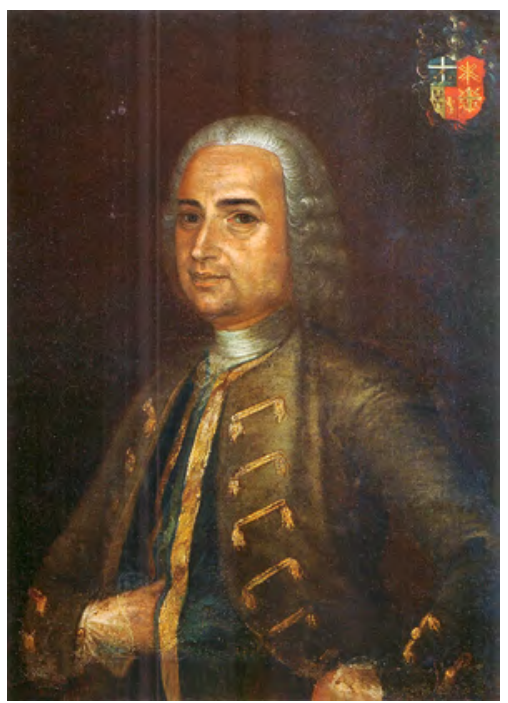

Fig. 6. Atribuido a Domingo Sánchez Carmona: Félix Poggio y Valcárcel.

Colección particular, Los Realejos.

belleza $^{54}$. Revela gran interés por la descripción que el artista hizo de sus joyas, sobre todo de los brazaletes con varios hilos de perlas que ciñen las muñecas y el collarete de oro con perlas y esmeraldas que porta al cuello, siendo la última una prenda que no perdió modernidad en el medio isleño hasta el siglo XIX $^{55}$.

Otro tanto acontece con la efigie de Félix Poggio, en la que se advierte, por el contrario, una indefinición mayor en el apartado técnico y lo propiamente figurativo. A ello contribuye la simplicidad del atuendo, compuesto en la casaca por un tejido liso que apenas recibe ornamento si exceptuamos los galones del extremo. Con todo, el modelo viste un elegante pańuelo-corbata al cuello, camisa que asoma con fino encaje a través de las mangas y peluca de grueso cabello recogido atrás, idónea para enfatizar las mismas facciones que delatan un manejo hábil del pincel por parte del pintor.

Los aportes de Domingo Sánchez Carmona al retrato de Canarias no terminan en esta suerte de imagen repetida o al uso, ya que en dos lienzos que le atribuimos ahora afloran condiciones de interés. El paralelismo de ambos con los cua-

${ }^{54}$ La definición de estos retratos y de otros afines no difiere de modelos comunes en el ámbito americano, tal y como ha puesto de relieve NúŃEZ MÉNDEZ, Elsaris (2013): «El retrato civil femenino. Imagen y representación de la mujer cristiana en la Nueva España (siglo xviII)», Barroco iberoamericano: identidades culturales de un imperio. Santiago de Compostela, t. I, pp. 215-230.

55 Pérez Morera, Jesús (2018): «La joya antigua en Canarias. Análisis a través de los tesoros marianos [II]», Anuario de Estudios Atlánticos, n. ${ }^{\circ}$ 64, pp. 26-28, 64-70/fig. 69. 
dros anteriores avala por sí solo esta nueva propuesta de catalogación, pero cobra sentido al conocer la identidad de los modelos: varios caballeros de la casa de Franchy, con los que el pintor convivió antes de morir en 1768. Al margen de ese hecho, las efigies resultan atractivas si nos atenemos al formato y al sentido conceptual que se les confirieron entonces.

El primero de ellos corresponde con el retrato oficioso de Juan Bautista de Franchy y Benítez de Lugo (1696-1767), segundo marqués de El Sauzal [fig. 7]. Suponemos que Domingo Carmona lo realizó al final de su vida y poco antes de que él mismo muriese en 1768, algo que parece confirmar el aspecto un modelo que en esos momentos había superado ya los setenta años de $\operatorname{edad}^{56}$. De entrada, la pintura sorprende por su formato oval y por dar cabida a características señaladas antes, entre las que no faltan el fondo neutro y la concreción depositada en la figura de un hombre rotundo en sus volúmenes corporales. En este caso aflora un detenimiento mayor por la recreación de las facciones, mucho más personalizadas que en efigies anteriores por medio de una papada prominente, la boca pequeńa, una nariz amplia y, sobre todo, ojos de gran tamaño que enfatizan las cuencas orbitales. De acuerdo a su estatus nobiliario, el modelo viste impecablemente conforme a los modismos en vigor e incorpora una peluca con poco predominio del cabello cano, el tricornio y una casaca de tejido labrado, acaso confeccionada con las sedas de origen europeo que tanto furor causaron en el Archipiélago años antes. A modo de rasgo distintivo, el pintor hace gala de una ligera indefinición de las formas, ya señalada por la ligereza con que maneja el pincel a la hora de recrear detalles como los galones de la casaca o el pañuelo-corbata que exigía la etiqueta nobiliaria.

Un modelo afín se localiza en otro retrato de la familia Franchy, a nuestro juicio un trabajo más de Sánchez Carmona y quizá pintado en La Orotava hacia 1765. Se trata del amplio cuadro de la Inmaculada junto a dos devotos que cuelga en la ermita de Nuestra Señora del Carmen o de Franchy, asignado antes a Feliciano de Abreu $^{57}$. Sin embargo, esa autoría no es factible por el estilo que manifiesta la obra ni por la apariencia conferida a ambos modelos en el plano inferior de la composición. Que se trata de un cuadro dieciochesco no cabe duda por el modo en que son concebidas las representaciones de un personaje noble con mediana edad y de un clérigo que muestra el hábito negro distintivo, ya en la vejez [fig. 7].

Las hipótesis para la identificación son diversas y, si en el caso del sacerdote el asunto no queda del todo claro, algunos investigadores defienden que la otra efigie podría representar al ya citado Juan Francisco Domingo de Franchy (1698-1774), «vecino principal de la Villa» que alojó al pintor en su domicilio ${ }^{58}$. Puestos a espe-

56 Nobiliario de Canarias..., op. cit., t. I, pp. 336-338; Cólogan Soriano, Carlos (2010): Los Cólogan de Irlanda y Tenerife. Santa Cruz de Tenerife, pp. 240-241.

57 Recoge esa filiación, entre otros, Luque Hernández, Antonio (1998): La Orotava, corazón de Tenerife. La Orotava, p. 285.

58 Esta idea la defiende también Luque Hernández, Antonio: La Orotava..., op. cit., p. 285. Para completar la biografía del personaje es conveniente la lectura de Nobiliario de Canarias..., op. cit., t. I, pp. 309-312; y Cólogan Soriano, Carlos: Los Cólogan..., op. cit., pp. 236-243. 
cular sobre esa idea, creemos probable que dicho personaje se corresponda en realidad con alguno de sus hijos, especialmente con Juan Antonio (1721-1766) o Antonio de Franchy y Ponte (1729-1808), ya que el modelo recreado describe la imagen de un varón que rondaba los cuarenta ańos de edad que ambos alcanzaron durante la década de 1760. En caso de figurar al primero, podría estimarse como un retrato próximo a la fecha de su fallecimiento repentino en el Puerto de la Cruz; y si se tratara de Antonio, la autoría queda respaldada al recordar que Carmona lo nombró albacea testamentario en marzo de $1768^{59}$.

En lo relativo al personaje noble, la indefinición de su aspecto guarda relación con otros trabajos de Domingo Sánchez Carmona. Además, muestra el atuendo característico de mediados del siglo xviII, ahora completo porque da cabida al tricornio y al bastón de mando que podría aludir a la ostentación de poder político en público. La imprecisión con que se recrean algunos detalles de los tejidos incide en esa idea, siendo extensible en el caso del otro efigiado a su pelo cano y al breviario que sostiene en una de las manos. Al margen de tal pormenor, ambos retratos son un trabajo afín y muy correcto en las formas, quizá artificioso por la representatividad que dichas imágenes ganan en una composición de innegable sentido piadoso.

Esa circunstancia motivó que figuraciones semejantes fueran estudiadas durante mucho tiempo con un criterio dispar, porque, más que orantes o donantes, estos retratos codifican una práctica al uso desde el siglo XV que perpetuaba el recuerdo de los modelos como hombres de fe. No se trata de imágenes creadas para la vanagloria, sino que, al contrario, su inclusión en cuadros de temática sacra nos previene sobre devociones particulares y la voluntad que muchos comitentes tuvieron de ser recordados como buenos cristianos. El fin de representaciones afines que contuvieron o no las manos unidas al pecho era la oración que podía hacerse por ellos a destiempo y, en consecuencia, por alentar la salvación de su alma como meta y último propósito vital ${ }^{60}$. De ahí que este ejemplar sea una obra atípica en el contexto insular y aliente la incorporación de ambos personajes con una efigie de algo más de medio cuerpo junto a un paisaje evocador, a ambos extremos del plano inferior y bajo la representación de la Inmaculada Concepción. La última queda enmarcada por cabezas angélicas de simple esbozo en un celaje que componen nubes de tonos grises y azules, matizadas siempre por toques de color blanco. Aunque es igualmente convencional en sus formas, la representación mariana se convierte en antecedente de los modos, tipos y soluciones iconográficas que Juan de Miranda (17231805) popularizará años después en obras de diverso acabado y tamaño ${ }^{61}$.

La elección de este tema para centrar el retrato de los Franchy podría explicarse a raíz del fervor inmaculista que alentaron la política religiosa de Carlos III y

59 Rodríguez Morales, Carlos: «El pintor Domingo...», art. cit., p. 517. Para conocer la trayectoria de ambos personajes, véase Nobiliario de Canarias..., op. cit., t. I, pp. 311-313.

${ }^{60}$ Una aproximación a estas cuestiones en FALQUe, Ingrid (2011): «Le portrait dévotionnel dans la peinture des Anciens Pays-Bas entre 1400 et 1550. Approche méthodologique pour une analyse du langage de l'image», Revue Belge d'Archéologie et d'Histoire de l'Art, n. ${ }^{\circ}$ Lxxx, pp. 77-97.

${ }^{61}$ Cfr. Rodríguez González, Margarita: La pintura..., op. cit., pp. 294-367. 
la proclamación de la Virgen María bajo dicho título como patrona de España desde 1761, aunque en el medio local tales circunstancias se adscriben a la devoción que muchos nobles -y entre ellos, varios miembros de la casa Franchy desde el siglo XVIprofesaron a la titular de la parroquia matriz de La Orotava. Durante la década de 1750 se debatía sobre la conveniencia de reedificar su fábrica y a dicho proceso quedaron vinculados pronto algunos parientes de Juan Francisco Domingo de Franchy, revelando así una sintonía con el mismo contexto de exaltación nobiliaria que evocan los retratos que Domingo Sánchez Carmona pudo pintar junto a la Virgen ${ }^{62}$.

Recibido: 28-03-2019. Aceptado: 11-04-2019

${ }^{62}$ Una descripción de ese contexto en Rumeu de Armas, Antonio (1997): «Patricio José García y Miguel García de Chaves, maestros arquitectos de la construcción de la iglesia de la Concepción de La Orotava», Anuario de Estudios Atlánticos, n. ${ }^{\circ} 43$, pp. 605-654. 